\title{
Comparative Study of Anti-Anemic Effect of Some Natural Food Supplements on Rats
}

\author{
Safaa Ahmed Salem ${ }^{1, *}$, Amany Mohammed Gad ${ }^{2,3}$, Abdellatif Anaam Kamal ${ }^{1}$ \\ ${ }^{1}$ Department of Medicinal Food, National Organization for Drug Control and Research (NODCAR), Giza, Egypt \\ ${ }^{2}$ Department Pharmacology, National Organization for Drug Control and Research (NODCAR), Giza, Egypt \\ ${ }^{3}$ Department of Pharmacology and Toxicology, Faculty of Pharmacy, East Kantara Branch, New City, El Ismailiaa, Egypt \\ Email address: \\ safyahmed211@yhoo.com (S. A. Salem), amanygd@yahoo.com (A. M. Gad), Enaamkamal@gmail.com (A. A. Kamal) \\ ${ }^{*}$ Corresponding author
}

\section{To cite this article:}

Safaa Ahmed Salem, Amany Mohammed Gad, Abdellatif Anaam Kamal. Comparative Study of Anti-Anemic Effect of Some Natural Food Supplements on Rats. International Journal of Food Science and Biotechnology. Vol. 6, No. 2, 2021, pp. 21-29.

doi: $10.11648 / j . i j f s b .20210602 .11$

Received: March 2, 2021; Accepted: March 24, 2021; Published: April 7, 2021

\begin{abstract}
In this study beetroot and eggplant were used as natural source for production of anti-anemic functional food for anemic patients and to prevent it during disease or chemotherapy treatment. Anemic model was induced in albino female rats by daily injection with phenylhydrazin $(5 \mathrm{mg} / \mathrm{kg} \mathrm{b.w)}$ for three successive days, then biochemical, hematological and histological parameters were determined including; iron, ferritin, Ascorbic acid, Hepicidin, Hemoglobin and Complete blood count (men corpuscle volume, men corpuscle hemoglobin, haematocriet, red blood cells and white blood cells). Negative control group of normal rats, and positive control group of anemic rats each of six rats were fed on basal diet. Also 24 anemic rats were divided into 4 groups each of 6 rats which were fed on basal diet containing either eggplant or beetroot in ratios of $100,300 \mathrm{~g} / \mathrm{kg}$, in addition to $500 \mathrm{mg}$ ascorbic acid and $2 \mathrm{mg}$ folic acid/ $\mathrm{kg}$ diet for all groups for 30 days. feeding period was 30 days. At the end of experiment the above biochemical and haematological parameters were evaluated and the liver and spleen were histopathological examined. Decreases in hemoglobin, men corpuscle volume, haematocriet, red blood cells, men corpuscle hemoglobin, iron, ascorbic acid and ferritin, also increases in white blood cells and hepcidin were observed in anemic model rats. At the end of feeding period with the previous supplemented tested basal diet, increases in all aforementioned parameters, except white blood cells and hepcidin which showed decreases compared to anemic positive group were found.
\end{abstract}

Keywords: Anemic, Beetroot, Chemical Properties, Eggplant, Hematological, Histopathologjcal

\section{Introduction}

Two billion people suffer from anemia worldwide and most of them have iron deficiency and hemolytic anemia due to toxicants and oxidants. About $70-80 \%$ of the world population, particularly in the developing countries, rely on nonconventional medicine like dietary supplements and herbal remedies in their primary healthcare [1].

Anemia is known to be an early and inevitable sign in patients with chronic kidney disease and can confer significant multiple adverse clinical consequences, morbidity and mortality [2]. Anemia is an important risk factor associated with the severity of illness of corona virus disease (covid-19), and healthcare should be sensitive to hemoglobin and iron levels of covid-19 on patients on admission [3].

Iron deficiency is a silent condition that causes anemia only when hemoglobin synthesis results impaired represents one of the major causes of anemia and affects around 20-30\% of adults worldwide [1] The relationship between anemia and the severity of covid-19 pneumonia is that's; compare to patients without anemia, patients with anemia were more comorbidities and sever covid-19 illness, as well as higher mortality covid-19 patients with anemia were predisposed to more sever inflammatory responses, coagulation disorders 
and organs injuries [4].

Anemia can reduce the work capacity of an individual or entire population, bringing serious economic consequences and obstacles to national development. The occurrence of cardiovascular and renal diseases with anemia is termed 'cardio - renal - anemia syndrome'. It is caused by a relative shortage of erythropoietin and can also be associated with disordered iron homeostasis caused by reduced iron absorption, occult blood loss and impaired iron mobilization [5], as well as chronic inflammation. Among the most important factors in the pathogenesis of iron metabolism defects is hepcidin as it maintains mammalian iron homeostasis [6]. Various methods for treating the anemia in laboratory animals have been used which include iron, although there are various drugs for the treatment of anemia, they are not affordable to many poor people especially those in the developing countries [7]. Among the most important nutrients deficiency can lead to nutritional anemia are iron, folic acid, vitamin B6, vitamin $\mathrm{B} 12$, vitamin $\mathrm{C}$ and protein.

In addition, the rural populations in various parts of the world do not have adequate access to high quality drugs for the treatment of anemia, so they depend heavily on plants and herbal products for the treatment of diseases and anemia. As a result of the fact that anemia is very common and the incidence is likely to increase in future, there is need to prevent it or seek for more cost-effective and better treatment strategies.

Phenylhydrazine (PHZ) is an antipyretic agent which as toxic dangerous action on red blood cells [8]. Exposure to phenylhydrazine causes damage to red blood cells, potentially resulting in anemia and consequential secondary involvement of other tissues, such as spleen and liver. PHZ induced hemolytic anemia which can be used as a model for the study of haematinic agents.

Today in food industry, modern technologies are used to change food products that provide additional health benefits to consumers. These products, namely "functional foods" are those that promise consumers improvement in targeted physiological functions.

Eggplant (Solanummelongena L.) is one of the most important vegetable crops, around 50 million tons are grown on over 1.7 ha million world-wide [9]. It is low in calories and has various macro- and micro-minerals which are beneficial for human health especially iron, compared to other commonly consumed vegetables [10].

Beetroot (Beta Vulgaris) is one of the most important vegetables consumed worldwide. Scientifically, beetroot is recognized to increase exercise stamina and increases running performance [11]. It is also utilized in management of hypertension [12]. Beetroot can be recognized for its antiradical, antimicrobial, cytotoxic activities and anti-hepatoprotective [12], also claimed as anti-diabetic potential effect. Due to its red color, traditionally, beetroot is claimed to be useful in haematological disorders, its juice has obvious nutritional, medicinal and health benefits, its also considered as rich supply of vitamins and minerals such as iron, magnesium and excellent source of folate [13].

\section{Materials and Methods}

\subsection{Materials}

Phenylhydrazine hydrochloride was purchased from Sigma Chemical Co. (St. Louis, MO, USA). All other chemicals were of the highest purity and analytical grade.

The fresh eggplant and beetroot as raw materials were purchased from local market, washed, cut into small pieces and dried in a hot air oven at $50^{\circ} \mathrm{C}$ for $48 \mathrm{~h}$. The dried samples were ground and passed through a sieve (20 mesh), and stored in a refrigerator until used.

\subsection{Analytical Methods}

Dry matter, total protein, crude fibers and ash were determined in raw materials according to the methods described by official methods of analysis [14], also minerals content including, iron, calcium and magnesium, were estimated using atomic absorption spectrometer, and vitamin $\mathrm{C}$ was determined by compleximetreic method according to A. O. A. C [14]. Vitamin B6, B12, and folate were determined by HPLC [15].

\subsection{Experimental Design and Protocol}

Forty eight female albino rats $(160-180 \mathrm{~g})$ were used, experiment was carried out in the animal house of National Organization for Drug Control and Research (NODCAR), Giza, Egypt. The investigation complies with the guide for the care and use laboratory animals (NIH publication NO. 85-23, revised 1996). Animals were housed in separate stainless steel cages and raised in a well-ventilated room with 12-h light/dark cycle with free access to food and water. The study protocol was approved by The Institutional Research Ethics Committee (NODCR-REC) at the National Organization of Drug Control and Research (NODCAR/I /21/2020). After adaptation period (7 days) in which rats was fed on basal diet, six rats were randomly chosen as initial group, blood samples were withdrawn from retro bulbar venous plexus of each rat according to the procedure of shermer, 1967 [16].

Serum was separated, then biochemical and haematological parameters were determined and rats were sacrificed, liver and spleen were excised and fixed in $10 \%$ formalin for the histopathological examination, six rats were kept as negative control group which was fed on basal diet during the experimental period.

\subsubsection{Induction of Anemic Model}

Haemolytic anemic model was induced in the remaining thirty six female rats by a daily intraperitoneal injection with PHZ (5 mg/kg b.w.) for3 days [17]. At the end of injection period six rats were randomly chosen, blood samples were taken, serum was separated, then biochemical and haematological parameters were determined to be sure that the anemic model was obtained. Anemia was 
considered to be induced when red blood cell (RBC) level as well as a hemoglobin (HB) concentration were reduced by about $30 \%$.

\subsubsection{Biological Evaluation of Tested Diet}

In addition to negative control group, rats were divided into five groups each of six rats as follow:

control $^{-}$: Rats fed on basal diet

control+: Anemic rats fed on basal diet

Group I: Anemic rats fed on basal diet containing 100gm eggplant/kg diet.

Group II: Anemic rats fed on basal diet containing $300 \mathrm{gm}$ eggplant $/ \mathrm{kg}$ diet.

Group III: Anemic rats fed on basal diet containing $100 \mathrm{gm}$ beetroot $/ \mathrm{kg}$ diet

GroupIV: Anemic rats fed on basal diet containing $300 \mathrm{gm}$ beetroot $/ \mathrm{kg}$ diet.

The diet in all tested groups was supplemented with 500 $\mathrm{mg}$ ascorbic acid and $2 \mathrm{mg}$ folic acid $/ \mathrm{kg}$ diet. Experimental period was 30 days.

At the end of experiment blood samples were withdrawn from the orbital plexus of eye of each rat in EDTA vials, serum was separated, the biochemical and haematological parameters were evaluated, then all rats were sacrificed, liver and spleen were excised and fixed in $10 \%$ formalin for the histopathological examination.

\subsubsection{Serum Biochemical Analyses}

Serum iron was estimated using commercial kit (BioDiagnostics, Giza, Egypt), and serum ferritin was estimated using commercially available ELISA kit. Ascorbic acid was estimated using commercial kit (Bio-Diagnostics, Giza, Egypt).

Hepicidin was estimated using commercially available ELISA kit (My Bio Source, San Diego, USA; Catalog Number: MBS732279). The procedures were conducted as stated in the manufacturer's instructions.

\subsubsection{Haematologicalparameters}

Hemoglobin was determined according to [18], and Complete blood count (MCV, MCH, HCT, RBCs and WBCs) was assessed by D cell Instrument for High Performance Testing (United Kingdom).

\subsection{Histopathological Method}

Specimens from liver and spleen were fixed in $10 \%$ formalin then dehydrated and embedded in paraffin for light microscopic examination. Sections of 5 micron thickness were cut and stained by Hematoxylin and Eosin (H\&E) for general histological structure and counterstain which was done using eosin stain [19].

\subsection{Statistical Analysis}

Data are presented as mean \pm standard error. The data were analyzed using one-way ANOVA, followed by Tukey post-hoc test, using Graph Pad Prism data analysis program (Graph Pad software, Inc., San Diego, CA, USA).
A value of $p \leq 0.05$ was considered statistically significant.

\section{Results and Discussion}

\subsection{Chemical Composition of Raw Materials}

In the current study, the fresh beetroots and eggplant were chemically analyzed for their nutrients; protein. fiber, ash, iron, calcium, magnesium, ascorbic acid and folate. The results are shown in table 1 . The content of dry matter was higher in beetroot (15.47\%) compared to eggplant (7.79\%), also ash content of beetroot and eggplant were 1.10 and $0.49 \%$, respectively. Crude protein was higher in beetroot than that in eggplant in percentage of 2.43 and 1.09, respectively. These results were approximately in agreement with those obtained by kale et al., 2018 [20] with some differences due to the variety of the genotypes. The percentage of fiber content in eggplant was higher than that in beetroot in value of 3.90 and 0.53 , respectively, these results were similar to those obtained by San José et al., 2016 [21].

Table 1. Chemical composition of fresh beet root and eggplant.

\begin{tabular}{lll}
\hline Parameters & beetroot & Eggplant \\
\hline Component $(\mathrm{g} / 100 \mathrm{~g}):$ & & \\
Dry matter & $15.47 \pm 0.66$ & $7.79 \pm 0.69$ \\
Protein & $2.43 \pm 0.15$ & $1.09 \pm 0.05$ \\
Fiber & $0.53 \pm 0.052$ & $3.90 \pm 0.23$ \\
Ash & $1.10 \pm 0.11$ & $0.49 \pm 0.02$ \\
Minerals $(\mathrm{mg} / 100 \mathrm{~g}):$ & & \\
Iron & $1.41 \pm 0.09$ & $0.67 \pm 0.01$ \\
Calcium & $16.32 \pm 0.44$ & $10.23 \pm 0.37$ \\
Magnasium & $0.82 \pm 0.01$ & $6.50 \pm 0.28$ \\
Vitamins $(\mathrm{mg} / 100 \mathrm{~g}):$ & & \\
Vit C & $7.65 \pm 0.57$ & $27.00 \pm 3.01$ \\
Vit B12 & $54.48 \pm 2.32$ & 0.00 \\
Vit B6 & $5.46 \pm 0.32$ & $0.081 \pm 0.004$ \\
Folate & $9.70 \pm 0.001$ & $0.020 \pm 0.88$ \\
\hline
\end{tabular}

Mean \pm S. E, $n=6$

Minerals composition of beetroot were analyzed and results revealed $1.41,16.32$ and $0.82 \mathrm{mg} / 100 \mathrm{~g}$ for iron, calcium and magnesium respectively. The results are in agreement with those found by Petek, et al., 2019 [22]. Also, eggplant values were $0.67,10.23$ and $6.5 \mathrm{mg} / 100 \mathrm{~g}$ for the three aforementioned minerals, respectively, different amount of iron in 25 genotype of eggplant in range of 0.199 $0.656 \mathrm{mg} / 100 \mathrm{~g}$ fresh weight were found and the range of magnesium was $5.15-20.4 \mathrm{mg} / 100 \mathrm{~g}$ fresh weight, the differentiation due to the genotype by Arivalagan et al., 2012 [23].

Minerals are important constituents of human diet as they serve as co-factors for many physiological and metabolic processes. Magnesium is an important co-factor of many regulatory enzymes and is fundamental in the energy transfer reactions involving high energy compounds as ATP and phosphate and thus prevent muscle contraction, pregnancyinduced hypertension and preeclampsia [24]. More than 2 
billion people worldwide are anemic, and this can be mainly attributed to iron deficiency in their dietary intake. Iron is essential to human health as it's a main component of body systems involved in the utilization of oxygen, its deficiency during childhood and adolescence impairs physical and mental development [25].

The data in table 1 showed the contents of ascorbic acid, B6, B12 and folate of the beetroot and eggplant. Mean value of ascorbic acid was high in eggplant $(27 \mathrm{mg} / 100 \mathrm{~g})$ in comparison with beetroot $(7.65 \mathrm{mg} / 100 \mathrm{~g})$, this result was in agreement with Abbaspour et al., 2014, Khanum et al., 2017 $[25,26]$.

Ascorbic acid is an important component of human diet, it is involved in the release of iron from ferritin. Also, vitamin B6 and B12 were in values of 5.46 and $54.48 \mathrm{mg} / 100 \mathrm{~g}$ in beetroot compared to 0.081 and $0.00 \mathrm{mg} / 100 \mathrm{~g}$ in eggplant, respectively as seen in table 1 . Dried beet green has been a rich source of vitamins B6, B12, and folic acid [27]. The chemical composition of this part was estimated to prepare a diet to reduce anemia caused by PHZ in rats, anti-anemic effect of dried beet green in phenylhydrazine treated rats was approved Elaby and Ali., 2018 [27]. On the other hand, the mean value of folate in beetroot and eggplant were 9.70 and $0.02 \mathrm{mg} / 100 \mathrm{~g}$, respectively. The results were in agreement with those reported by [21].

\subsection{Induction of Anemic Animal Model}

Induction of anemic rats model by PHZ affected haematological biomarkers and biochemical parameters and induced anemic model rats by significant decrease in $\mathrm{HB}$, $\mathrm{MCV}, \mathrm{MCH}, \mathrm{HCT}$ and RBCs concentrations in addition to iron, ascorbic acid and ferritin in serum, compared to initial group. PHZ induce destruction of red blood cells by oxidation stress and many joint changes at cellular levels resulting in haemolyticanemia. PHZ induced toxic anemia presented a model for research of pathogenesis of hemolytic anemia and the influence of anemia on other physiological processes [8].

Results in table 2 showed the decrement in all aforementioned haematological and biochemical parameters in values of 10.22, 63.13, 22.27, 31.03, 2.88, 50.33, 4.20 and 1.33 in the anemic model compared to initial group in values of $14.80,91.57,32.13,46.60,5.67,109.10,12.00$ and 2.50 respectively. Also an increment in both WBCs and hepicidin was obseved in values of 15.03 and 157.4 in anemic group compared to initial group in values of 10.75 and 40.85 in the two parameters respectively.

Phenylhydrazin was used for many years in the experiments for induction of anemia in animals, it induced anemia as a model for the study of haematinic effect; it decreases HB, RBCs and impairs erethocyte deformability, vit $\mathrm{C}$ is also decreased in oxidative stress caused by PHZ in vitro [28].
Table 2. Changes in biochemical and haematological parameters in anemic rast model.

\begin{tabular}{lll}
\hline Parameter & Initial & Anemic \\
\hline $\mathrm{HB}(\mathrm{g} / \mathrm{dl})$ & $14.80 \pm 0.109$ & $10.22 \pm 0.19$ \\
$\mathrm{MCV}(\mathrm{FI})$ & $91.57 \pm 1.369$ & $63.13 \pm 1.28$ \\
$\mathrm{MCH}(\mathrm{pg})$ & $32.13 \pm 1.126$ & $22.27 \pm 0.928$ \\
$\mathrm{HCT} \%$ & $46.60 \pm 0.680$ & $31.03 \pm 0.240$ \\
$\mathrm{WBCs}\left(\mathrm{cmm} \times 10^{3}\right)$ & $10.75 \pm 0.150$ & $15.03 \pm 0.160$ \\
$\mathrm{RBCs}\left(\mathrm{cmm} \times 10^{6}\right)$ & $5.67 \pm 0.296$ & $2.88 \pm 0.263$ \\
$\mathrm{IRON}(\mu \mathrm{mol} / \mathrm{dl})$ & $109.10 \pm 3.50$ & $50.33 \pm 3.093$ \\
Ascorbic acid $(\mathrm{mg} / \mathrm{ml})$ & $12.00 \pm 0.70$ & $4.20 \pm 0.3742$ \\
Hepcidin $(\mathrm{Pg} / \mathrm{ml})$ & $40.85 \pm 2.450$ & $157.40 \pm 8.05$ \\
Ferritin & $2.50 \pm 0.22$ & $1.33 \pm 0.210$ \\
\hline
\end{tabular}

Mean \pm S. E, $n=6$

\subsection{Biological Evaluation of Supplemented Food}

\subsubsection{Effect on Haematological Markers}

Induction of anemic rats caused significant decrease in $\mathrm{HB}$, HCT, RBCs, MCV and MCH as seen in table 2. Feeding on the tested supplemented diet showed significant increases in the five parameters in all groups as seen in figure 1, the best results were found in group IV with non significant changes compared to negative control group, group II comet in the second place with little decrease compared to group IV and negative control, while group I and III showed significant decreaces compared to negative control, group II and IV, and non significant change was found between them, only MCV showed non significant changes among the three tested groups I, II and III. PHZ causes oxidative damage to red blood cells by increasing the formation of reactive oxygen species [29]. Feeding with different amount of beetroot or eggplant resulted in increased values of all of the aboves paramters. All the previous results indicate that both the beetroot and eggplant contain some bioactive agents that are powerful antioxidants that either prevent or repair the damage done to the cells by free radicals or highly reactive oxygen species [30], Beetroot has the ability to stimulate erythropoietin and restore red cell parameters to normal [31]. concentration significantly increased in anemic mice fed on beetroot $(400 \mathrm{mg} / \mathrm{kg})$ compared with irradiation-induced anemic mice [32].

\subsubsection{Effect on WBCs Concentration}

Induction of anemic model by injection with PHZ caused significantly increased total leucocytes count compared to initial group as seen in table 2. Interestingly, these elevations were completely averted by feeding with eggplant or beetroot in a dose dependent manner. The values of WBCs in all tested groups were returned back compared to negative control value with non-significant different among them as seen in figure 2A. The result was in agreement with Elaby and Ali., 2018 [27]. 

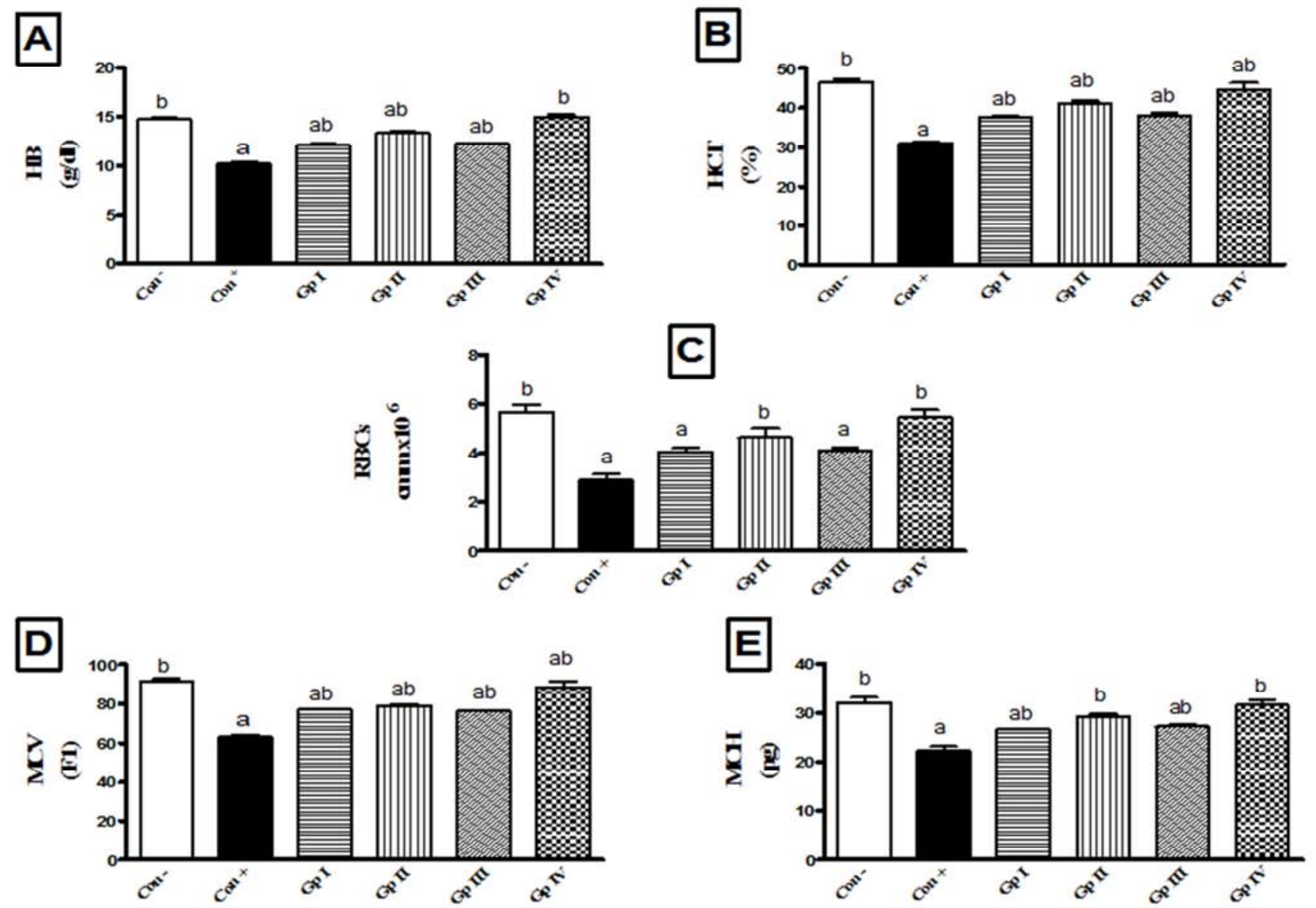

Figure 1. (A-E) Effect of eggplant and beetroot on HB (Panel; A), HCT (Panel; B), RBCs (Panel; C), MCV (Panel; D) and MCH (Panel; E) levels in anemic rats.

Con: Rats fed on basal diet.

$\mathrm{Con}^{+}$: Anemic rats fed on basal diet.

Gp I: Anemic rats fed on basal diet $+100 \mathrm{~g}$ eggplant. + ascorbic acid and folic acid

Gp II: Anemic rats fed on basal diet $+300 \mathrm{~g}$ eggplant.+ ascorbic acid and folic acid Gp III: Anemic rats fed on basal diet $+100 \mathrm{~g}$ beetroot. + ascorbic acid and folic acid Gp IV: Anemic rats fed on basal diet $+300 \mathrm{~g}$ beetroot. + ascorbic acid and folic acid mean $\pm \mathrm{SE}$, $(\mathrm{n}=6)$. a, b, c, d e: Significantly different from negative or positive control, Gp I, Gp II, Gp III an Gp IV, respectively at $\mathrm{P}<0.05$ using one way ANOVA followed by Tukey as post-hoc tes

\subsubsection{Effect on Iron, Ferritin and Ascorbic Acid Concentrations}

Induction of anemic rats' model by injection with PHZ to rats caused a significant decline in iron, ferritin and ascorbic acid concentrations compared to initial group as seen in table 2.

Feeding on the tested supplemented diet containing eggplant or beetroot showed very highly significant increase of iron in group IV compared to negative and positive control, followed by group II, while group I and III come in the third place with non-significant changes between them as seen in figure 2B-D. Also, significant increases in ferritin in all groups were found, the best results were observed in groups IV and II with non-significant changes between them and non-significant changes compared to negative control. Also, significant increase in ascorbic acid was detected and the best results were found in group IV and II with non-significant change between them and their values higher than that in negative control (figure 2B-D). Beetroot and eggplant have ameliorative effects on Cyclophosphamide-induced anemia in rats. Supplementation with diet rich in vegetables like eggplant may increase consumption of antioxidants including carotenoids, ascorbate, tocopherol and phenolics which were found to inhibit the cellular damage induced by oxidative stress [34], Also eggplant constituents especially vitamin C could have been responsible for the inhibition of cell damage [35]. Tropical eggplant diet could have a holistic effect on various pathology as a result of its abundant polyphenol constituents and its low glycemic index, which could serve as therapeutic functional food that can be used to manage hepatic inflammation. Feeding with eggplant increased vitamin $\mathrm{C}$ activity in experimental type 2 diabetic animal model that indicate its anti diabetes, antihypertensive and antioxidant properties [36]. Many people worldwide are 
anemic, and this can be mainly attributed to iron deficiency. Iron is an essential component of body system involved in the utilization of oxygen. Iron deficiency during childhood and adolescence impairs physical and mental development [37]. Anemia and level of iron may be play a role in multiple organ dysfunction syndrome in covid-19, therefore public strategies designed to protect the patients that could be a risk of covid-19 complications.

On the other hand, the study showed after 20 days taking 8 $\mathrm{g}$ of beetroot the level of total iron binding capacity decreased and serum iron levels increased. This indicates that beetroot is an excellent source of iron [27].
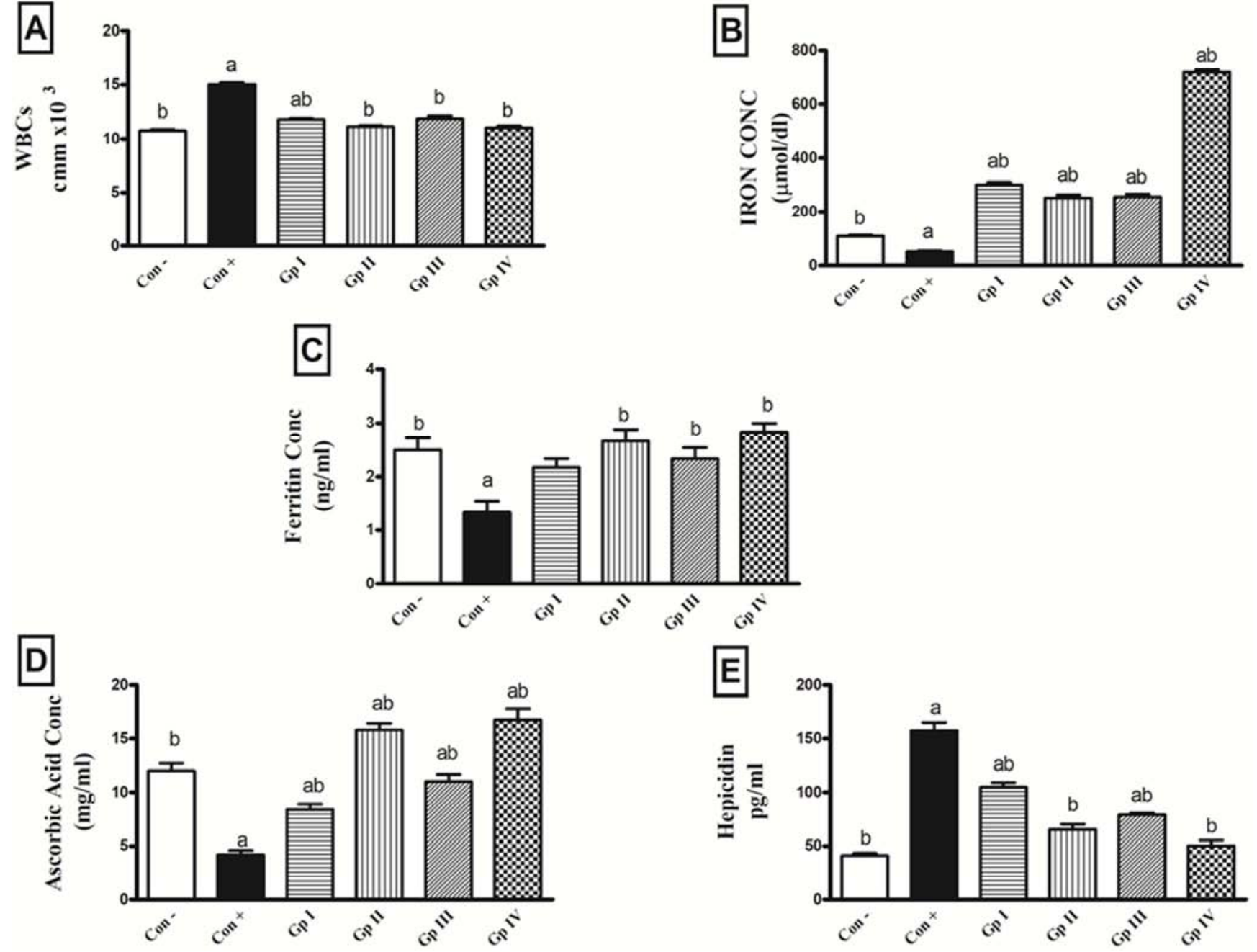

Figure 2. (A-E). Effect of eggplant and beetroot onWBCs count (Panel; A), iron (Panel; B), ferritin (Panel; C) and ascorbic acid (Panel; D) concentrations as well as hepcidin level (Panel; E) in rats subjected to PHZ administration. Mean $\pm S E, n=6$ Groups abbreviation as seen in figure $1 a, b, c$, $d$, e, significantly different from negative or positive control at $p<0.05$.

\subsubsection{Effect on Hepcidin}

It was found that induction of anemic model with PHZ injection induced significant increase in hepcidin level compared to initial group as seen in table 2. Feeding on supplemented eggplant or beetroot showed significant decrease in all groups compared to anemic rats, the best results were found in the group which was fed on supplemented beetroot $(30 \%)$ with non-significant change compared to negative control group, followed by group II which was fed on supplemented diet containing eggplant $(30 \%)$ as seen in figure 2E. Hepicidin, a 25-amino acid peptide hormone was produced primarily by hepatocytes, the principal regulator of iron homeostasis in health and during inflammation. Excessive production of this hormone causes iron sequestration in macrophages and hypo ferremia, as was shown in transgenic mice with hepicidin over expression [33]. Hepicidin, dramatically increase in inflammatory conditions and is a major factor in anemia of chronic diseases [34]. Excessive production of hepicidin causes iron deficiency anemia as a result of the individual's inability to absorb iron, despite normal or even iron-enriched diet [35] anemia, hypoxia, and inflammation were reported to influence hepicidin expression [36]. Treatment with eggplant or beetroot decreased hepicidin level in a dose dependent manner which might be attributed to the anti inflammatory effects of these agents [37].

\subsubsection{Preparation of Beetroot Juice}

From the obtained results in this study, it was clear that 
supplemented beetroot showed the best results concerning its effect on biochemical and haematological parameters to improve the anemia in rats. Therefore beetroot was chosen to be used in preparing supplemented food in addition to vit $\mathrm{C}$ and folic acid. Beetroot powder in amount equivalent to daily human dose which can be reconstituted in water to obtain beetroot juice used as functional food for prevention and treatment anemia.

\subsubsection{Effect of Concurrent Administration of GpI and GpII on Histopathological Examination of Liver and Spleen}

A. Liver

Liver sections of rats from control group showed the normal

A. LIVER
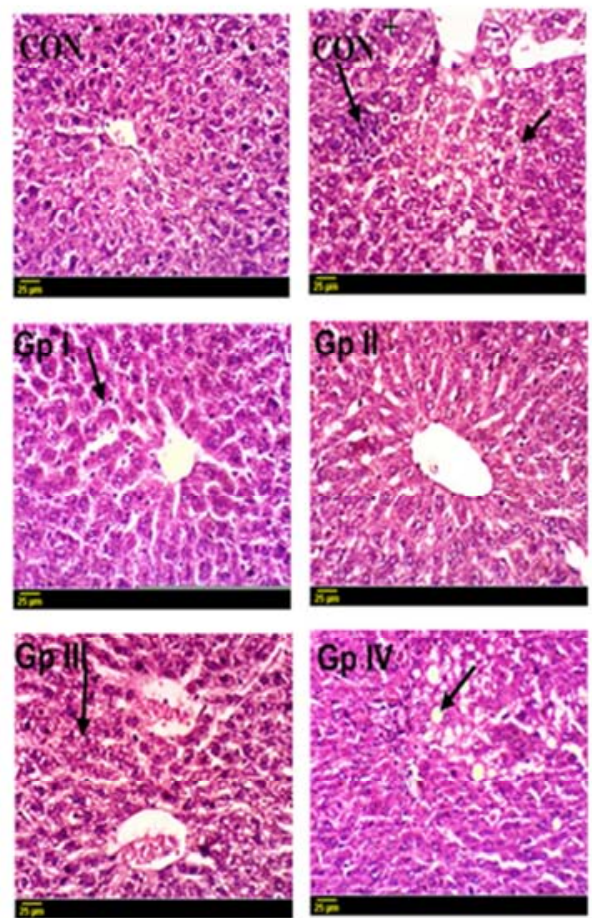

histological structure of hepatic lobule from central vein and hepatic cords. On the contrary, liver sections from PHZ group showed vacuolar degeneration of hepatocytes and focal mononuclear cell infiltration. However, GpI and GpII preserved the normal architecture of the liver when given concurrently with PHZ in a dose dependent manner (Figure 3).

\section{B. Spleen}

Spleen sections of rats from control groups have normal white pulp. On the contary, spleen sections from $\mathrm{PHZ}$ group showed lymphocytic necrosis and depletion with appearance of tangible body macrophages. However, GPI and GPII preserved the normal architecture of the spleen when given concurrently with PHZ in a dose dependent manner (Figure 3).

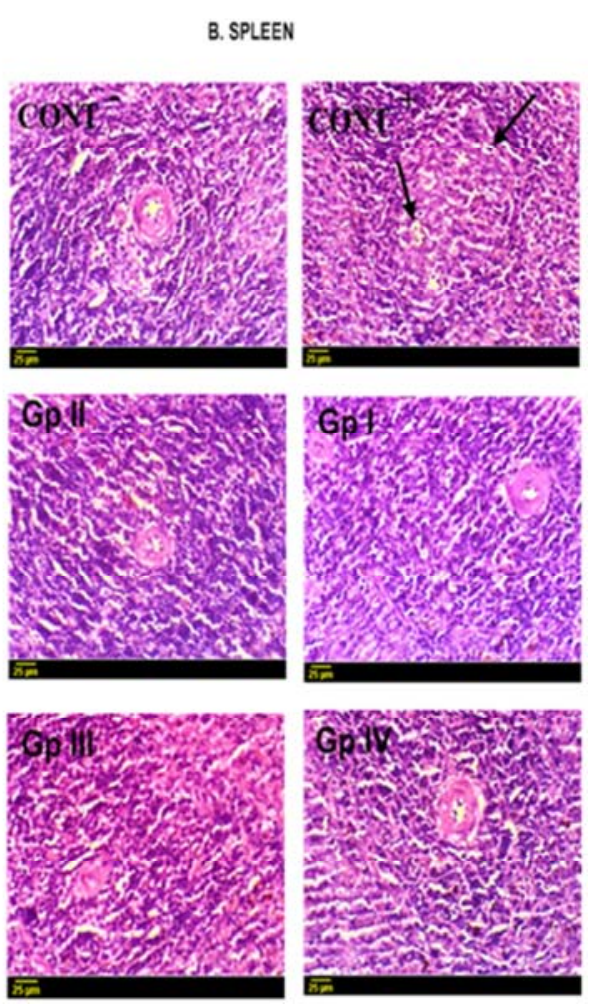

Figure 3. Histopathological changes in liver and spleen of phenylhydrazine-induced anemic rats fed experimental diets. (cont): fed basal diet. (cont $\left.{ }^{+}\right)$: anemic rats fed on basal diet. (GPI): anemic rats fed on basal diet containing100 gm eggplant /kg diet, (GpII): anemic rats fed on basal diet containing300 gm eggplant / $\mathrm{kg}$ diet. (Gp III): anemic rats fed on basal diet containing100 gm beetroot $/ \mathrm{kg}$ diet. (GpIV): anemic rats fed on basal diet containing $300 \mathrm{gm}$ beetroot $/ \mathrm{kg}$ diet. all tested diet rats supplemented with ascorbic acid and folic acid.

\section{Conclusion}

This study revealed that administration of beetroot or eggplant for anemic model rats induced by PHZ restored normal values of haematologicl parameters, also increased; iron, ascorbic acid, ferritin and hampering the hepicidin, moreover prevented the histopathological alterations in liver and spleen. Both the above nutritional source are considered as antianemic natural source, which can be used in production of functional food, that can helps in treatment of anemia disease, also in decrease or prevention of anemia incidence in patients during chemotherapy treatment and for covid-19 patients to reduce the severity of illness and complication.

\section{Acknowledgements}

The authors sincerely acknowledge their gratitude to the efforts of Pathology Department, Faculty of Veterinary Medicine of Cairo University and National organization for drug control and research (NODCAR).

\section{References}

[1] Chauhan, SP, Sheth, NR, Suhagia, BN (2015). Hematinic effect of fruits of Opuntia elatior Mill. on phenylhydrazineinduced anemia in rats," AYU (An Int. Q. J. Res. Ayurveda. 36 (2): 208-213. 
[2] Ali, B, Al Za'abi M, Ramkumar A, Yasin J, Nemmar, A (2014). Anemia in adenine-induced chronic renal failure and the influence of treatment with gum acacia thereon. Physiol. Res. 63 (3): 351-358.

[3] Petek, ET, Sergio, A G, Erand, L, Peter, Francis, R, Lyda, Z R, Beatrice, MW, Doris, KH, Wolf, EH, Michele, F E, Oscar, HF, Marija, G, Taulant, M. (2020). Anemia and iron metabolism in COVID- 19: A systematic review and meta- analysis. 35 (8): 763-773.

[4] Zheying, T, Mingyu, L, Jingyi, W, Jing, X, Wei, C, Zhitao, Y, Ling, L, Ruwu, C, Jingyuan, X, Huiming, W, Jialin, L.(2019) "Anaemia is Associated with Severe Illness in COVID-19: A Retrospective Cohort Study. Res. Sq.

[5] Ruedin, P, Dickenmann, M, Martin, P, Wüthrich, R. (2012). Management of renal anemia in patients with chronic kidney disease: the role of the general practitioner. Rev. Med. Suisse. 8 (323): 70-73.

[6] Pantopoulos, K, Porwal, S K, Tartakoff, A, Devireddy, L. (2012). Mechanisms of mammalian iron homeostasis. Biochem. 51:. 5705-5724.

[7] Ogbe, R, Adoga, G, Abu, A. (2010). Antianaemic potentials of some plant extracts on phenyl hydrazine-induced anaemia in rabbits. $J$. Med. Plants Res. 4 (8): 680-684.

[8] Berger, J. (2007). Phenylhydrazine haematotoxicity. J. Appl. Biomed. 5 (3): 125-130.

[9] Rubatzky, VE, Yamaguchi, M. (2012). World vegetables: principles, production, and nutritive values Springer Sci. Bus. Media.

[10] Kowalska, G., Wiercinski, J. (2003). Chemical composition of fruits of three eggplant (Solanum melongena L.) cultivars. Folia Hortic. (Poland). 15 (2) 89-95.

[11] Siervo, M, Lara, J, Ogbonmwan, I., Mathers, JC. (2013). Inorganic Nitrate and Beetroot Juice Supplementation Reduces Blood Pressure in Adults: A Systematic Review and Meta-Analysis. J. Nutr. 143 (6): 818-826.

[12] J. M. Čanadanović-Brunet et al.(2011) "Antioxidant and antimicrobial activities of beet root pomace extracts. Czech J. Food Sci. 29 (6): 575-585.

[13] Sahore K, Rani S. (2019). A review on medicinal importance, pharmacological activity and toxicology ofNutraceuticals. 8 (2): 441-449.

[14] A. O. A. C, "fficial methods of analysis of AOAC international $20^{\text {th }}$ (ed) current through revision 2. Atkinson, M. A. \& furth, S. L. 2011.

[15] Szterk A, Roszko M, Małek K, Czerwonka M, WaszkiewiczRobak B. (2012). Application of the SPE reversed phase HPLC/MS technique to determine vitamin B12 bio-active forms in beef. Meat Sci. 91: 408-413.

[16] Shermer G, Jones KC. (1967). Public Housing is the Tenants," Washington, DC Natl. Assoc. Hous. Redev. Off.

[17] Musyoka T, Dorothy N, Wycliffe A, Juma K, Nzioka M. (2016). In Vivo Antianaemic Effect and Safety of Aqueous Extracts of Erythrina abyssinica and Zanthoxylum usambarensis in Mice Models. J. Hemato Thromboembolic Dis. 4 (3): 1-10.

[18] Drabkin, D L, Austin, J. H. (1935). Spectrophotometric studies II. Preparations from washed blood cells; nitric oxide hemoglobin and sulfhemoglobin. J Biol. Chem. 112 (1): 51-65.
[19] Bancroft J, Gamble M. (2008). Theory and practice of histology techniques. Churchill Livingstone Elsevier. 83-134.

[20] Kale, R, Sawate, A, Kshirsagar, R, Patil, B., Mane, R. (2018). Studies on evaluation of physical and chemical composition of beetroot (Beta vulgaris L.)," International journal of chemical studies. 6 (2): 2977-2979.

[21] San José R, Plazas M, Sánchez-Mata MC, Cámara M, Prohens J. (2016). Diversity in composition of scarlet (S. aethiopicum) and gboma (S. macrocarpon) eggplants and of interspecific hybrids between $\mathrm{S}$. aethiopicum and common eggplant (S. melongena), J. Food Compos. Anal. 45: 130-140.

[22] Petek, M, Toth, N, Pecina, M., Karažija, T, Lazarević, B, Palčić, I, Veres, S., Ćustić, M H. (2019). Beetroot mineral composition affected by mineral and organic fertilization. PLoS One. 6: 1-15.

[23] Arivalagan M., Gangopadhyay K., Kuma, G., Bhardwa, R., Prasad T., Sarkar S. K., Roy (2012). Variability in mineral composition of Indian eggplant (Solanum melongena L.) genotypes," Journal of Food Composition and Analysis. 26 (1-2): 173-176.

[24] Wolk, R, Shamsuzzaman, A S, Somers, VK. (2003). Obesity, sleep apnea, and hypertension. Hypertension. 42: 1067-1074.

[25] Abbaspour N, Hurrell R, Kelishadi R (2014). Review on iron and its importance for human health. J. Res. Med. Sci. 19 (2): 164-174.

[26] Khanum F, Anand T, Ilaiyaraja N, et al. (2017). Health Food for Soldiers. Def. Life Sci. Journal. 2 (2): 111-119.

[27] Elaby SM, Ali JB. (2018). The anti-anemic effect of dried beet green in phenylhydrazine treated rats. Arch. Pharm. Sci. Ain Shams Univ. 2 (2): 54-69.

[28] Claro LM, Leonart MSS, Comar SR, do Nascimento AJ. (2006). Effect of vitamins $\mathrm{C}$ and $\mathrm{E}$ on oxidative processes in human erythrocytes. Cell Biochem. Funct. 24 (6): 531-535.

[29] Pingali P, Srinivas P, Reddy M. (2015). Study of anti-anaemic effect of Schrebera Swietenioides roxb. In rat models," Asian J. Pharm. Clin. Res. 8 (5) 305-308.

[30] Gheith, I, El-Mahmoudy, A. (2018). Laboratory evidence for the hematopoietic potential of Beta vulgaris leaf and stalk extract in a phenylhydrazine model of anemia," Brazilian J. Med. Biol. Res. Rev. Bras. Pesqui. medicas Biol. 51 (11): 1-8.

[31] Beshel, FN, Beshel, J A, Ante, E E. (2018). The Ethanolic Extract of Beetroot (Beta Vulgaris) Ameliorates Some Red Cell Parameters In Phenylhydrazine-Induced Anaemic Rats. IOSR J. Nurs. Heal. Sci. 7 (4): 27-30.

[32] Jinhee, C, So, J B, Areum, K, Nam, H L, Sang-Hee, B, Gi-Ok, $\mathrm{K}$, Youngheun, J. Beetroot (Beta vulgaris) rescues mice from $\gamma$-ray irradiation by accelerating hematopoiesis and curtailing immunosuppression. Pharm Biol. 55 (1): 306-316.

[33] Roy CN, Mak HH, Akpan I, Losyev G, Zurakowski D, Andrews NC. (2007). Hepcidin antimicrobial peptide transgenic mice exhibit features of the anemia of inflammation. Blood. 109 (9) 4038-4044.

[34] Weinstein DA, Roy CN, Fleming MD, Loda MF, Wolfsdorf JI, Andrews NC. (2002). Inappropriate expression of hepcidin is associated with iron refractory anemia: Implications for the anemia of chronic disease. Blood. 100 (10): 3776-3781. 
[35] Vokurka M, Krijt J, Šulc K, Nečas E. (2006). Hepcidin mRNA levels in mouse liver respond to inhibition of erythropoiesis. Physiol. Res. 55 (6): 667-674.

[36] Ganz T. (2007). Molecular control of iron transport. J. Am. Soc. Nephrol. 18 (2): 394-400.
[37] Nwanna EE, Ibukun EO, Oboh G. (2016). Effect of some Tropical Eggplant Fruits (Solanum Spp) Supplemented Diet On Diabetic Neuropathy In Experimental male Wistar Rats Invivo,. Functional Foods in Health and Disease. 6 (10): 661676. 